\title{
Analysis of Adverse Effects on Performance due to Battery Deterioration Installed in BEV and HEV
}

\author{
Yushi Kamiya, Yusuke Sumida and Yasuhiro Daisho \\ Graduate School of Environment and Energy Engineering, Waseda University, Tokyo 169-8555, Japan
}

Received: May 10, 2013 / Accepted: July 09, 2013 / Published: January 31, 2014.

\begin{abstract}
This paper reports the results of investigating the permissible amount of battery deterioration. An investigation was carried out using the following two types of vehicles: a BEV (battery electric vehicle) and a HEV (hybrid electric vehicle). First, a detailed evaluation was carried out to identify how the vehicle performance was adversely affected as the lithium-ion batteries installed in the vehicles deteriorated. Next, an attempt was made to determine the permissible amount of deterioration for the vehicle-mounted lithium-ion batteries. In the case of the BEV, the driving distance declined by $20 \%$ when the capacity maintenance rate was approximately $80 \%$. Therefore, this was specified as the permissible amount of battery deterioration for the BEV. In the case of the $\mathrm{HEV}$, the fuel consumption increased by $20 \%$ when the maximum battery output maintenance rate was approximately $40 \%$. Therefore, this was specified as the permissible amount of battery deterioration for the HEV.
\end{abstract}

Key words: BEV (battery electric vehicle), HEV (hybrid electric vehicle), lithium battery, vehicle performance.

\section{Introduction}

In recent years, there has been a strong shift toward electric-driven vehicles from the standpoint of addressing environmental and energy problems [1]. The battery of an electric-driven vehicle is considered to be the heart of this type vehicle [2] and this paper collects together and reports the results of investigating the permissible amount of battery deterioration.

When the battery installed in an electric-driven vehicle deteriorates, the power and environmental performance of the vehicle naturally become worse [3]. However, the performance aspects that become worse and the degree of deterioration vary greatly depending on the type of vehicle. For example, if batteries with the same deterioration characteristics are installed in an electric vehicle [4] and in a hybrid vehicle, the aspects of vehicle performance that become worse as the batteries deteriorate are completely different. Consequently, studies of the permissible amount of

Corresponding author: Yushi Kamiya, doctor of engineering, professor, research fields: BEV, HEV, PHEV, LIB and wireless charging system. E-mail: kamiya@waseda.jp. battery deterioration must consider the special characteristics of the decline in vehicle performance as well as the permissible amount of deterioration for each type of vehicle [5-8].

Accordingly, an investigation was carried out using the following two types of vehicles: a BEV (battery electric vehicle) and a HEV (hybrid electric vehicle). First, a detailed evaluation was carried out via a numerical value simulation $[9,10]$ to identify how the vehicle performance was adversely affected as the lithium-ion batteries installed in the vehicles deteriorated (i.e., battery capacity deterioration and internal resistance deterioration). Next, an attempt was made to determine the permissible amount of deterioration for the vehicle-mounted lithium-ion batteries based on the data that was obtained and the requirements for each type of vehicle.

\section{Details of Simulation}

\subsection{Specifications of Target Vehicles and Simulation Outline}

Table 1 shows the specifications of the BEV and 
HEV used in this investigation. The HEV is assumed to be a passenger vehicle equipped with a series-parallel hybrid system [9]. The HEV simulation model reproduces the power split device mounted on the vehicle that links the motor, engine and generator, as well as various phenomena such as engine cranking (Fig. 1). In addition, the driving mode used in this investigation was the JC08 test cycle [11].

\subsection{Engine ON and Warm-up Conditions for HEV}

Table 2 shows the engine ON conditions for the HEV. The engine was operated along the operating curve after turning on Ref. [10].

The engine was warmed up after the start of driving. Engine power during warm-up is dedicated to warming up the catalyst, and the battery is responsible for providing the power required by the vehicle [10].

\subsection{Target Battery}

Figs. 2 and 3 show the SOC (state of charge) dependency of the open-circuit voltage and internal resistance per single cell within the batteries installed in each type of electric vehicle. These are based on factors such as the discharge characteristics of commercially-available batteries for BEVs and HEVs and are applied to each vehicle [12]. The internal resistance is also corrected in accordance with the capacity of the assumed battery system [2]. In this investigation, the upper and lower limits of the terminal voltage were set and the maximum permissible charge and discharge rates for each type of vehicle were also limited. Table 3 shows these battery conditions.

This paper defines the battery capacity in relation to the capacity of a new battery as the capacity maintenance rate Cs (\%). The internal resistance increase rate, Rs (\%) is also defined in the same way. Capacity deterioration and internal resistance deterioration both progress at the same time under actual vehicle usage conditions, so the progress ratio was determined based on the results of a storage capacity loss test [3]. Battery SOC is determined based
Table 1 Vehicle specifications.

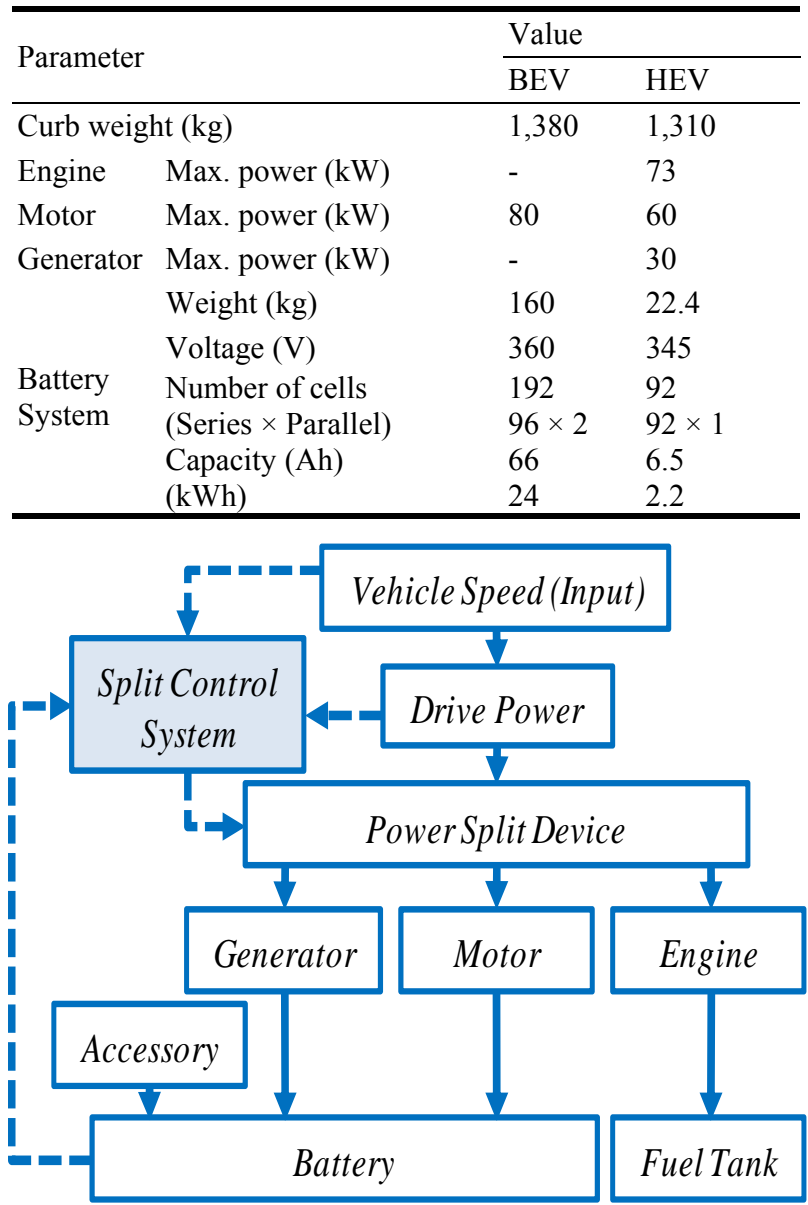

Fig. 1 HEV simulation model.

Table 2 HEV's engine ON conditions.

\begin{tabular}{|c|c|}
\hline High (SOC $50 \%$ or over) & Low (SOC under 50\%) \\
\hline $\begin{array}{l}\text { - Drive power: } 15 \mathrm{~kW} \\
\text { or over } \\
\mathbf{\Delta} \text { Vehicle speed: } 55 \mathrm{~km} / \mathrm{h} \\
\text { or over } \\
\text { (Engine stops } \\
\text { @ SOC } 52.5 \% \text { or over) }\end{array}$ & $\begin{array}{l}\text {-Drive power: } 10 \mathrm{~kW} \\
\text { or over } \\
\Delta \text { Vehicle speed: } 25 \mathrm{~km} / \mathrm{h} \\
\text { or over } \\
\text {-SOC: under } 47.5 \%\end{array}$ \\
\hline
\end{tabular}

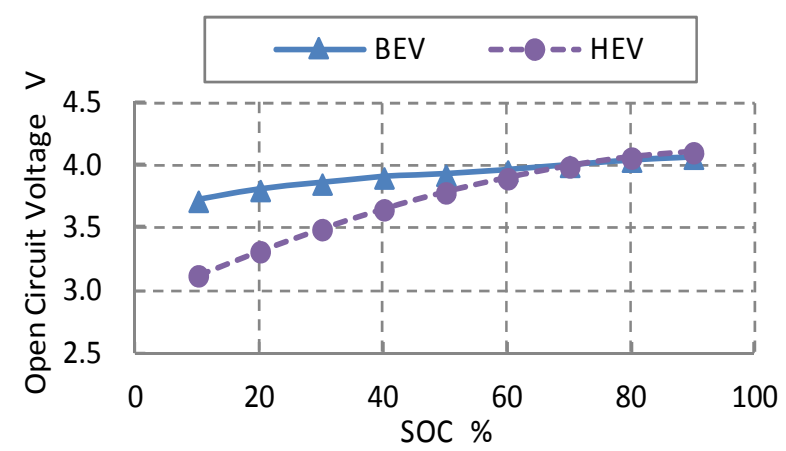

Fig. 2 Characteristics of open circuit voltage of lithium-ion battery (single cell). 


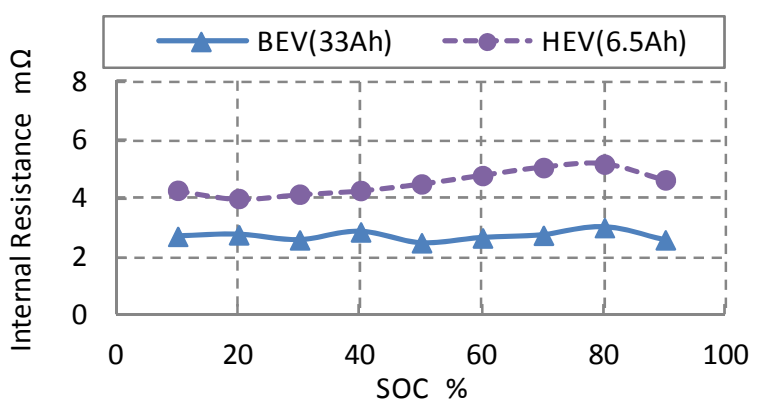

Fig. 3 Characteristics of internal resistance of lithium-ion battery (single cell).

Table 3 Conditions of lithium-ion battery (single cell).

\begin{tabular}{lll}
\hline Parameter & \multicolumn{2}{l}{ Value } \\
\cline { 2 - 3 } & BEV & HEV \\
\hline Upper limit voltage (V) & 4.3 & \\
Lower limit voltage (V) & 2.5 & \\
Max. discharge rate (C) & 5 & 20 \\
Max. charge rate (C) & 3 & 20 \\
\hline
\end{tabular}

on the battery capacity when new and after deterioration. Furthermore, it was assumed that battery capacity deterioration does not affect the SOC dependency of the open-circuit voltage [4].

\section{Adverse Effects on Vehicle Performance when Battery Deterioration Progresses}

This chapter summarizes the results from analyzing and evaluating the adverse effects of lithium-ion battery deterioration (simulated based on capacity and internal resistance deterioration) on the performance of each of the vehicles.

\subsection{Adverse Effect on BEV Performance}

\subsubsection{Target Vehicle Performance}

The following BEV performance aspects were analyzed: (1) output (satisfying the maximum required output of the JC08 test cycle); (2) electricity consumption rate; (3) driving distance on a single charge. A BEV is driven only by an electric motor, which makes it different from a HEV or PHEV, which have engines. Therefore, it is necessary to confirm that the output performance of the battery is sufficient, even when battery deterioration has progressed. The electricity consumption rate $E_{C R}(\mathrm{Wh} / \mathrm{km})$, and driving distance on a single charge $R_{D}(\mathrm{~km})$, are representative performance values for a $\mathrm{BEV}$, so naturally these were also selected. Here, the electricity consumption rate is defined by the following equation:

$$
E_{C R}=E_{C} / R_{D}
$$

$E_{C}(\mathrm{kWh})$ is the amount of electricity consumed in a single charge. In this paper, this is defined as the amount of energy needed to fully charge the battery after the vehicle is driven and the electricity in the battery used up.

\subsubsection{Effect of Battery Deterioration}

First, (1) output performance was analyzed. Fig. 4 shows the relationship between battery deterioration and maximum output. The maximum output of the battery is restricted by the permissible maximum discharge rate and also by the lower limit voltage. It decreases as the internal resistance increases. In this investigation, the maximum required output of the $\mathrm{JC} 08$ test cycle is approximately $22 \mathrm{~kW}$. It was concluded that the battery could sufficiently satisfy this required output even when the internal resistance increasing rate was approximately $500 \%$.

Fig. 5 shows the increase in (2) electricity consumption rate and the decrease in (3) driving distance on a single charge due to battery deterioration. In addition, to analyze the effects of capacity deterioration and internal resistance deterioration separately, Tables 4 and 5 show the results obtained when the type of deterioration progresses individually. The rate of electricity consumption increase was approximately $10 \%$, even when the capacity maintenance rate was $40 \%$ (the internal resistance increasing rate was approximately $500 \%$ at this time). As shown in Table 5, this increase is due to the greater Joule loss caused by the internal resistance deterioration. However, the decline in driving distance on a single charge was approximately $60 \%$ when the capacity maintenance rate was $40 \%$ (the internal resistance increasing rate was approximately $500 \%$ at this time). This is mainly due to battery capacity deterioration, as 


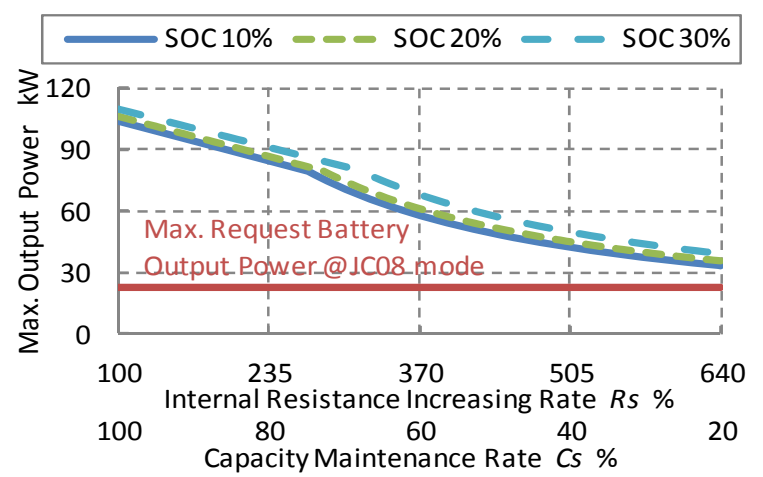

Fig. 4 Relationship between battery deterioration and max. output power of BEVs battery system.

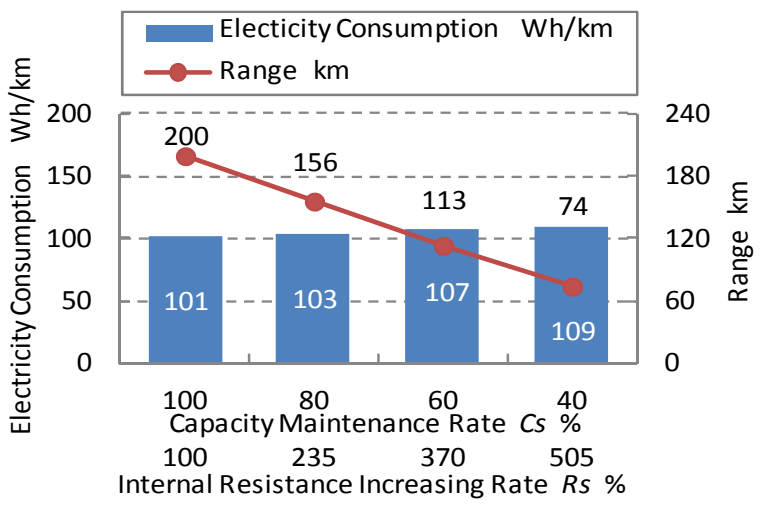

Fig. 5 Relationship between battery deterioration and vehicle performance of BEVs.

Table 4 Relationship between capacity maintenance rate and vehicle performance of BEVs.

\begin{tabular}{|c|c|c|c|c|}
\hline $\begin{array}{l}\text { Cs } \\
(\%)\end{array}$ & $\begin{array}{l}\text { Req. } \\
\text { Power@ } \\
\text { JC08mode }\end{array}$ & $\begin{array}{l}E_{C R} \\
(\mathrm{Wh} / \mathrm{km})\end{array}$ & $\begin{array}{l}1 / E_{C R} \\
(\mathrm{~km} / \mathrm{kWh})\end{array}$ & $\begin{array}{l}R_{D} \\
(\mathrm{~km})\end{array}$ \\
\hline 100 & satisfied & 101 & 9.93 & 200 \\
\hline 80 & satisfied & $\begin{array}{l}100 \\
(-0.33 \%)\end{array}$ & $\begin{array}{l}9.97 \\
(+0.33 \%)\end{array}$ & $\begin{array}{l}160 \\
(-20 \%)\end{array}$ \\
\hline 60 & satisfied & $\begin{array}{l}100 \\
(-0.37 \%)\end{array}$ & $\begin{array}{l}9.97 \\
(+0.38 \%)\end{array}$ & $\begin{array}{l}120 \\
(-40 \%)\end{array}$ \\
\hline 40 & satisfied & $\begin{array}{l}101 \\
(+0.12 \%)\end{array}$ & $\begin{array}{l}9.92 \\
(-0.12 \%)\end{array}$ & $\begin{array}{l}80 \\
(-60 \%)\end{array}$ \\
\hline
\end{tabular}

Table 5 Relationship between internal resistance increasing rate and vehicle performance of BEVs.

\begin{tabular}{lllll}
\hline $\begin{array}{l}R s \\
(\%)\end{array}$ & $\begin{array}{l}\text { Req. } \\
\text { Power@ } \\
\text { JC08mode }\end{array}$ & $\begin{array}{l}E_{C R} \\
(\mathrm{Wh} / \mathrm{km})\end{array}$ & $\begin{array}{l}1 / E_{C R} \\
(\mathrm{~km} / \mathrm{kWh})\end{array}$ & $\begin{array}{l}R_{D} \\
(\mathrm{~km})\end{array}$ \\
\hline 100 & satisfied & 101 & 9.93 & 200 \\
& & 103 & 9.76 & 196 \\
200 & satisfied & $(+1.8 \%)$ & $\begin{array}{l}(-1.8 \%) \\
(-1.6 \%)\end{array}$ \\
300 & \multirow{2}{*}{ satisfied } & 104 & 9.59 & 193 \\
& & $(+3.6 \%)$ & $(-3.5 \%)$ & $(-3.1 \%)$ \\
400 & satisfied & 107 & 9.35 & 189 \\
& & $(+6.2 \%)$ & $(-5.9 \%)$ & $(-5.2 \%)$ \\
500 & \multirow{2}{*}{ satisfied } & 109 & 9.17 & 186 \\
& & $(+8.3 \%)$ & $(-7.7 \%)$ & $(-6.8 \%)$ \\
\hline
\end{tabular}

shown in Table 4. Therefore, the rate of decline in driving distance is naturally equal to the rate of decline in the capacity.

These results show that the aspect of $\mathrm{BEV}$ performance most susceptible to battery deterioration is driving distance on a single charge. Furthermore, the dominant battery deterioration factor that causes this decline in performance is battery capacity deterioration.

\subsection{Adverse Effect on HEV Performance}

\subsubsection{Target Vehicle Performance}

Unlike a motor-driven BEV, a HEV also uses an engine. Therefore, even if the output performance of the battery deteriorates, it can still satisfy the output requirements of the vehicle. Therefore, an investigation concerning the maximum required output in the JC08 test cycle was not carried out for the HEV. In this case, fuel consumption $F_{C R}(L / 100 \mathrm{~km})$ was selected as the performance aspect to be analyzed. If the engine operation rate rises in order to compensate for insufficient output from the battery due to a decline in battery performance, then fuel consumption will increase. A decline in the energy regeneration rate will also cause fuel consumption to increase. Therefore, a comprehensive evaluation could be performed based on the effects of these phenomena by analyzing fuel consumption.

\subsubsection{Effect of Battery Deterioration}

Table 6 shows the relationship between battery capacity deterioration and increasing fuel consumption. This table also shows the amount of engine operating time and the electricity regeneration rate (the ratio of electricity that is regenerated, which is derived by considering the decline in battery input performance, with respect to the electricity that can charged by regeneration) in one JC08 test cycle. These results confirmed that fuel consumption worsened slightly when the capacity retention was $40 \%$. This is because the SOC is more susceptible to fluctuation when the battery capacity decreases, which increases the frequency at which a SOC of $52.5 \%$ is reached. Since the signal to switch the engine off is transmitted when 
Table 6 Relationship between capacity maintenance rate and vehicle performance of HEVs.

\begin{tabular}{|c|c|c|c|c|}
\hline $\begin{array}{l}\text { Cs } \\
(\%)\end{array}$ & $\begin{array}{l}F_{C R} \\
(\mathrm{~L} / 100 \mathrm{~km})\end{array}$ & $\begin{array}{l}1 / F_{C R} \\
(\mathrm{~km} / \mathrm{L})\end{array}$ & $\begin{array}{l}\text { Engine } \\
\text { ON } \\
\text { time (s) }\end{array}$ & $\begin{array}{l}\text { Max. } \\
\text { regeneration } \\
\text { rate }(\%)\end{array}$ \\
\hline 100 & 3.07 & 32.6 & 281 & 100 \\
\hline 80 & $\begin{array}{l}3.08 \\
(+0.37 \%)\end{array}$ & $\begin{array}{l}32.5 \\
(-0.36 \%)\end{array}$ & $\begin{array}{l}282 \\
(+0.07 \%)\end{array}$ & 100 \\
\hline 60 & $\begin{array}{l}3.10 \\
(+1.0 \%)\end{array}$ & $\begin{array}{l}32.3 \\
(-1.0 \%)\end{array}$ & $\begin{array}{l}279 \\
(-0.82 \%)\end{array}$ & 100 \\
\hline 40 & $\begin{array}{l}3.13 \\
(+1.9 \%)\end{array}$ & $\begin{array}{l}32.0 \\
(-1.8 \%)\end{array}$ & $\begin{array}{l}275 \\
(-2.2 \%)\end{array}$ & 100 \\
\hline
\end{tabular}

the SOC reaches $52.5 \%$, the number of times that the engine is turned $\mathrm{ON}$ and OFF also increases. This also leads to an increase in engine cranking, which involves large current flows, and causes an increase in internal resistance loss. However, the results also show that battery capacity deterioration has a very minor effect on vehicle performance.

Table 7 shows the relationship between battery internal resistance deterioration and increasing fuel consumption and so on. Fuel consumption declines due to an increase in internal resistance for the following reasons. The first reason is that both the charge and discharge efficiency of the battery decline. The second reason is that when the internal resistance increase reaches $300 \%$ or higher, the power for charging the battery when the vehicle decelerates is limited. It is possible to recover all regenerated power when the battery is new, but the maximum regeneration rate is greatly reduced when the internal resistance increases. This results in a reduction in fuel consumption. Finally, the third reason for the reduction in fuel consumption is that the engine $\mathrm{ON}$ time increases. Furthermore, increased engine cranking also reduces fuel consumption. However, compared to the three reasons described above, the adverse effect of additional engine cranking is only minor.

Fig. 6 shows the relationship between battery deterioration and increasing fuel consumption. The rate of fuel consumption increase is approximately $20 \%$ when the internal resistance increasing rate is approximately $500 \%$ (the capacity maintenance rate was $40 \%$ at this time).
Table 7 Relationship between internal resistance increasing rate and vehicle performance of HEVs.

\begin{tabular}{|c|c|c|c|c|}
\hline $\begin{array}{l}\text { Rs } \\
(\%)\end{array}$ & $\begin{array}{l}F_{C R} \\
(\mathrm{~L} / 100 \mathrm{~km})\end{array}$ & $\begin{array}{l}1 / F_{C R} \\
(\mathrm{~km} / \mathrm{L})\end{array}$ & $\begin{array}{l}\text { Engine } \\
\text { ON } \\
\text { time (s) }\end{array}$ & $\begin{array}{l}\text { Max. } \\
\text { regeneration } \\
\text { rate }(\%)\end{array}$ \\
\hline 100 & 3.07 & 32.6 & 281 & 100 \\
\hline 200 & $\begin{array}{l}3.17 \\
(+3.2 \%)\end{array}$ & $\begin{array}{l}31.6 \\
(-3.1 \%)\end{array}$ & $\begin{array}{l}287 \\
(+1.2 \%)\end{array}$ & 100 \\
\hline 300 & $\begin{array}{l}3.33 \\
(+8.4 \%)\end{array}$ & $\begin{array}{l}30.1 \\
(-7.8 \%)\end{array}$ & $\begin{array}{l}299 \\
(+6.1 \%)\end{array}$ & 99.6 \\
\hline 400 & $\begin{array}{l}3.56 \\
(+16 \%)\end{array}$ & $\begin{array}{l}28.1 \\
(-14 \%)\end{array}$ & $\begin{array}{l}311 \\
(+11 \%)\end{array}$ & 97.1 \\
\hline 500 & $\begin{array}{l}3.70 \\
(+21 \%)\end{array}$ & $\begin{array}{l}27.0 \\
(-17 \%)\end{array}$ & $\begin{array}{l}314 \\
(+12 \%)\end{array}$ & 93.1 \\
\hline
\end{tabular}

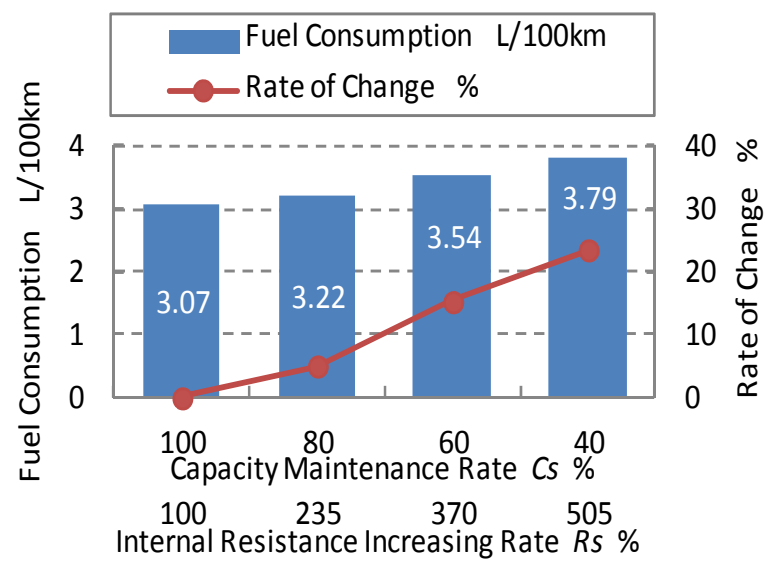

Fig. 6 Relationship between battery deterioration and vehicle performance of HEVs.

These results show that the aspect of HEV performance most susceptible to battery deterioration is fuel consumption. Furthermore, the dominant battery deterioration factor that causes this decline in performance is internal resistance deterioration.

\section{Investigation of Amount of Permissible Battery Deterioration for Each Type of Vehicle}

This section investigates the permissible amount of battery deterioration for each type of vehicle. Here, the following investigation procedure was set to enable uniform processing.

First, the most important aspect of vehicle performance to be used to determine the amount of permissible battery deterioration was specified for each type of vehicle. This is determined based on factors such as the requirements of the vehicle and the strength of the adverse effects of battery deterioration on the 
various aspects of vehicle performance. Next, the dominant deterioration factor (either battery capacity deterioration or internal resistance deterioration) that causes the decline in the selected vehicle performance was specified. Here, the maximum battery output maintenance rate $P_{s}(\%)$ is also used. This is an easy-to-understand index equivalent to internal resistance deterioration. Finally, the size of the deterioration factor after a $20 \%$ decline in the selected vehicle performance was defined as the permissible amount of battery deterioration [5]. The results obtained from the investigation of the permissible amount of battery deterioration for each type of vehicle are summarized below.

In the case of the BEV, based on the results of the analysis described above, driving distance on a single charge was selected as the vehicle performance aspect for determining the permissible amount of battery deterioration. The battery deterioration factor with the largest effect on driving distance was battery capacity deterioration. The simulation results in Fig. 7 show that driving distance on a single charge declined by $20 \%$ when the capacity maintenance rate was approximately $80 \%$. Therefore, this was specified as the permissible amount of battery deterioration for the BEV.

In the case of the HEV, fuel consumption was selected as the vehicle performance aspect for determining the permissible amount of battery deterioration. The battery deterioration factor with the largest effect on fuel consumption was internal resistance deterioration. The simulation results in Fig. 8 show that fuel consumption increased by $20 \%$ when the maximum battery output maintenance rate was approximately $40 \%$ (equivalent to an internal resistance increasing rate of approximately $450 \%$ ). Therefore, this was specified as the permissible amount of battery deterioration for the HEV.

\section{Conclusions}

The conclusions obtained the study described in this paper are summarized below:

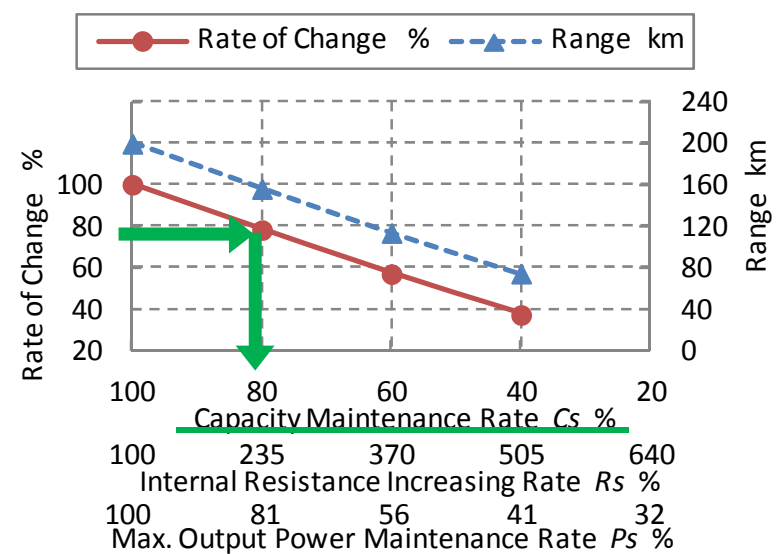

Fig. 7 Relationship between Range and BEV's Battery Deterioration.

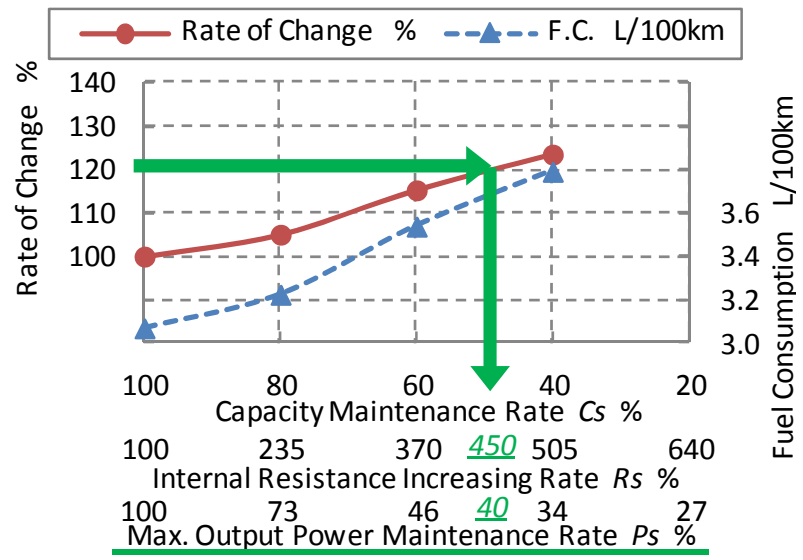

Fig. 8 Relationship between Fuel Consumption and HEV's Battery Deterioration.

(1) In the case of the BEV, the key vehicle performance aspect susceptible to battery deterioration was driving distance on a single charge. The dominant battery deterioration factor that caused this decline in vehicle performance was battery capacity deterioration. In this investigation, a $20 \%$ decline in driving distance on a single charge occurred when the capacity maintenance rate was approximately $80 \%$. Therefore, this was specified as the permissible amount of battery deterioration for the BEV.

(2) In the case of the HEV, the key vehicle performance aspect susceptible to battery deterioration was fuel consumption. The dominant battery deterioration factor that caused this decline in vehicle performance was internal resistance deterioration. In this investigation, $20 \%$ fuel consumption increase 
occurred when the maximum battery output maintenance rate was approximately $40 \%$. Therefore, this was specified as the permissible amount of battery deterioration for the HEV.

\section{References}

[1] S. Abe, Development of the Hybrid Vehicle and Its Future Expectation, SAE 2000-01-C042, 2000.

[2] T. Nishina, Express Charging/Discharging Lithium Ion Secondary Batteries, FB Technical News, No. 64, 2008.

[3] K. Takei, Trend and application of lithium secondary batteries, The Journal of the Institute of Electrical Engineers of Japan 5 (2010) 280-284.

[4] Y. Hirota, S. Adachi, S. Ogasawara, Y. Deguchi, Model-Based Control System Design for Electric Vehicles, Tokyo Denki University Press, Japan, 2009.

[5] Cycle Life Test Procedure of Sealed Nickel-Metal Hydride Batteries for Electric Vehicles, Japan Electric Vehicle Standard D708, JARI, 1999.

[6] Dynamic Capacity Test Procedure of Sealed Nickel-Metal
Hydride Batteries for Electric Vehicles, Japan Electric Vehicle Standard D709, JARI, 1999.

[7] Charge Retention Test Procedure of Sealed Nickel-Metal Hydride Batteries for Hybrid Electric Vehicles, Japan Electric Vehicle Standard D715, JARI, 2003.

[8] Cycle Life Test Procedure of Sealed Nickel-Metal Hydride Batteries for Hybrid Electric Vehicles, Japan Electric Vehicle Standard D716, JARI, 2004.

[9] Y. Wada, S. Shimada, W. Jibin, Y. Kamiya, Y. Daisho, K. Morita, Environmental performance evaluation of plug-in hybrid electric vehicles, World Electric Vehicle Journal 3 (2009) 1-8.

[10] H. Kinoto, H. Ochiai, H. Matsumura, Y. Kamiya, Y. Daisho, K. Morita, Examination on the permissible deterioration of lithium-ion battery installed in plug-in hybrid electric vehicles, JSAE Transaction 43 (2) (2012) 491-496.

[11] Test Method for Light and Medium-Duty Motor Vehicle Fuel Consumption Rate (Test method for JC08-mode Fuel Consumption), TRIAS, 2009.

[12] GS YUASA Products Catalogue, Industrial Lithium-Ion Secondary Batteries, 2011. 